\title{
Correction: Temporal dynamics of miRNAs in human DLPFC and its association with miRNA dysregulation in schizophrenia
}

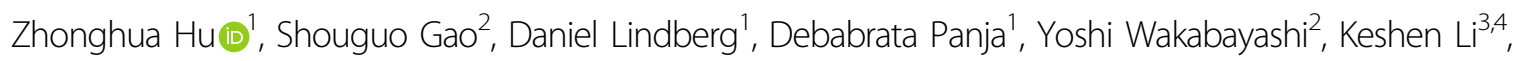
Joel E. Kleinman', Jun Zhu' ${ }^{5}$ and Zheng Li $^{1}$

\section{Correction to: Translational Psychiatry}

https://doi.org/10.1038/s41398-019-0538-y

published online 20 August 2019

In the original article, author Shouguo Gao's name was incorrectly stated as "Shuoguo Gao." This has been updated in the XML, HTML, and PDF versions of this article.

Published online: 23 September 2019

Correspondence: Jun Zhu (jun.zhu@nih.gov) or Zheng Li (lizheng2@mail.nih.gov)

${ }^{1}$ Section on Synapse Development and Plasticity, National Institute of Mental

Health, National Institutes of Health, Bethesda, MD 20892, USA

${ }^{2}$ Systems Biology Center, National Heart Lung and Blood Institute, National

Institutes of Health, Bethesda, MD 20892, USA

${ }^{3}$ Institute of Neurology, Affiliated Hospital of Guangdong Medical University,

Zhanjiang, Guangdong, China

${ }^{4}$ Clinical Neuroscience Institute of Jinan University, Guangzhou, China

${ }^{5}$ Lieber Institute for Brain Development, Baltimore, MD 21205, USA

These authors contributed equally: Zhonghua Hu, Shouguo Gao

\section{(c) The Author(s) 2019}

(c) (i) Open Access This article is licensed under a Creative Commons Attribution 4.0 International License, which permits use, sharing, adaptation, distribution and reproduction in any medium or format, as long as you give appropriate credit to the original author(s) and the source, provide a link to the Creative Commons license, and indicate if changes were made. The images or other third party material in this article are included in the article's Creative Commons license, unless indicated otherwise in a credit line to the material. If material is not included in the article's Creative Commons license and your intended use is not permitted by statutory regulation or exceeds the permitted use, you will need to obtain permission directly from the copyright holder. To view a copy of this license, visit http://creativecommons.org/licenses/by/4.0/. 